Article

\title{
HYRES: A Multi-Objective Optimization Tool for Proper Configuration of Renewable Hybrid Energy Systems
}

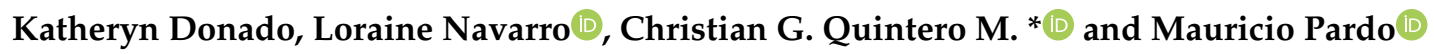 \\ Dept. of Electrical and Electronics Engineering, Universidad del Norte, Barranquilla 081007, Colombia; \\ katherynd@uninorte.edu.co (K.D.); lorainen@uninorte.edu.co (L.N.); mpardo@uninorte.edu.co (M.P.) \\ * Correspondence: christianq@uninorte.edu.co
}

Received: 28 October 2019; Accepted: 11 December 2019; Published: 19 December 2019

\begin{abstract}
This paper presents the Hybrid Renewable Energy System (HYRES), a powerful tool to contribute to the viability analysis of energy systems involving renewable generators. HYRES considers various input parameters related to climatic conditions, statistical reliability, and economic views; in addition to offering multi-objective optimizations using Genetic Algorithms (GAs) that have a better cost-benefit ratio than mono-objective optimization, which is the technique used in several commercial systems like HOMER, a worldwide leader in microgrid modeling. The use of intelligent techniques in HYRES allows optimal sizing of hybrid renewable systems with wind and solar energy generators adapted to different conditions and case studies. The elements that affect the system design like buying and selling energy from/to the grid and the use of storage units can be included in system configuration according to the need. Optimization approaches are selectable and include Initial Cost, Life Cycle Cost, Loss of Power Probability, and Loss of Power Supply Probability.
\end{abstract}

Keywords: adaptability; computational tool for renewable systems; genetic algorithms; hybrid wind-solar energy system; reliability; multi-objective optimization

\section{Introduction}

Power balance between sources and loads rules the behavior of any energy power system where equilibrium is essential for proper operation. Changing the power offering and/or modifying the load profile can alter the power balance which can produce generator malfunctions, not regulation compliance, power blackouts, among others. Thus, designing solar or wind-based systems adds extra challenges because the power offering becomes intermittent due to the nature of these power supplies. Therefore, promoting renewable energy generation systems requires more robust, resistant, manageable, and reliable schemes that complement known systems and architectures. One of such schemes involves the setup of hybrid system configurations that complement well-known generators with the use of renewable sources, which are more sustainable and can be fully available depending on the geographic location. In literature, it has been demonstrated effective hybrid systems for satisfying specific energy requirements. In any case, the system design procedure must be based on the prediction of the renewable energy resources data; therefore, the selection and sizing of the system components is optimized to trade-off system operation and investment costs.

Hence, hybrid system design becomes dependent not only on the geographical location, which conditions available area for solar panels and wind turbines and grid service connection, but also, on weather that modifies the quantity and type of elements that comprise the system. Then, design optimization is required to further adjust system configuration. Such optimization procedure may be focused on low cost, high efficiency, or both. 
Several studies have been carried out around hybrid systems considering solar and wind energy. This topic is currently widely researched due to its multiple benefits, highlighting among them the ability to generate clean energy for off-grid systems and decrease the billed energy in its support to grid-connected systems. For grid-connected systems, Bayod-Rújula et al. [1] analyze the parameter influence of a grid-connected hybrid solar-wind system with energy storage. This work proves the importance of hybrid systems and the reliability and cost reductions in comparison with non-hybrid systems. Proper sizing becomes a key element to maximize cost reduction related to invested money and lower electrical line loses. González et al. [2] work with Genetic Algorithms (GAs) for system optimization using the Net Present Value (NPV) as mono-objective function, and solar-panel area and number of wind turbines as parameters. Sinha and Chandel [3] and Khare et al. [4] present a review of hybrid solar grid-connected systems where depending on the optimization technique, different accuracy and system configuration/operation time are obtained. Therefore, the most used optimization approaches are divided into reliability criteria and cost analysis methods.

For off-grid hybrid solar-wind systems, Belmili et al. [5] develop software to size a system under a technical-economic point-of-view, and the optimization is based on the Loss of Power Supply Probability (LPSP) approach. Weather data is taken from NASA given the coordinates of the target zone, and the user must provide the technical parameters of the solar-wind equipment. Ma, Yang, and $\mathrm{Lu}$ [6] present a feasibility study and techno-economic evaluation for a remote island in Hong Kong. The simulations are done via HOMER software, and the optimization approach is the Levelized Cost of Energy (COE). Al Busaidi et al. [7] review the techniques used to optimize hybrid systems, and in terms of optimization, conventional techniques, and artificial intelligent techniques are compared. Thus, in this study; it is recommended to use hybrid systems due to the increase of reliability and decrease of Initial Capital Cost (ICC) and Life Cycle Cost (LCC). Conti et al. [8] presents an optimization strategy and the cost-optimal design of an off-grid building served by an energy system involving solar technologies, thermal, and electrochemical storages. Authors optimize a hybrid renewable energy system serving a reference off-grid small-to-medium accommodation facility, according to a multi-objective perspective: the minimization of Non Renewable Energy Systems (No-RES) energy consumption and maximization of NPV at the end of system lifetime.

For both, off-grid and grid connected systems there are also several studies. Xu et al. [9] develop an optimal system for grid-connected and off-grid schemes, looking for achieving high power supply reliability, making full use of the complementary characteristics of wind and solar, ensuring a small fluctuation of power injected into the grid, optimizing the Battery State Of Charge (SOC), and minimizing the total cost of the system. The optimization is made with an accurate and reasonable optimal sizing model built with the consideration of the required installation area of diesel generators (DGs) and the operating reserve capacity of the system along to a mono-objective optimization approach to minimize system costs.

Saharia et al. [10] work on a renewable energy system for electrification of a school; and the system is proved as a stand-alone scheme and as a grid-connected system optimized via HOMER. This work shows that the cost of energy is higher when operating in stand-alone mode. However, as the fossil fuel reserves are a limited resource and with a gradual cost increase in the future, balanced utilization of renewable and grid-connected system is seen to be the optimum configuration for the selected site.

Faccio et al. [11] present a review of recent works on optimal design of hybrid renewable energy systems. The cost factor is the most common optimization goal, together with environmental emissions. Only in a few cases was optimized the operation of a specific component (e.g., the electric battery). In [12], the authors review the main methodologies used for the optimization, highlighting positive aspects and drawbacks of each modeling technique, such as linear programming, particle swarm optimization, Monte Carlo analyses, and hybrid techniques. Recent reviews on optimization techniques applied in the design of hybrid renewable energy systems [13] present a general trend in analyzing, classifying, and developing novel algorithms according to their ability to handle high-dimension variable spaces $[14,15]$. 
Thus, in this paper; the assessment and optimization of a hybrid solar-wind power generation system are presented dividing the complete process into methodological stages targeting the best possible configuration (financial and technical). Thus, first; evaluation of the weather conditions is important because they will set the available power than later the electrical system will deliver. Then, the proper selection of mathematical models and technologies is carried out according to the desired accuracy of the whole system. Finally, optimization methods are used to select the configuration that better satisfies user needs and restrictions. To that end, the use of Genetic Algorithms is preferred given the superior suitability for optimization of solar-wind systems according to the literature. Next, the development of a system for different scenarios with different restrictions and configurations that optimally size the solar-wind hybrid system is shown. Within the allowed scenarios, there are grid-connected and off-grid systems. In addition, each one of them has the option of having a storage system or not. A new method of analyzing reliability with weather conditions is implemented which allows having two different kinds of reliability (annually and daily). The elements type, amount, and reference (brand, model) can be optimized. The system presented is not subject of specific possibilities because it is adaptable and flexible according to the needs of each particular scenario.

\section{System Configuration}

There are different configurations of hybrid systems with renewable energy sources according to the user needs. However, dimensioning each of these configurations supposes a different approach for each case. For this paper, the proposed hybrid system is shown in Figure 1. The main components of the system are solar panels and wind generators, an optional battery bank (to save electricity for low generation periods), an inverter, and the grid, which can be become optional.

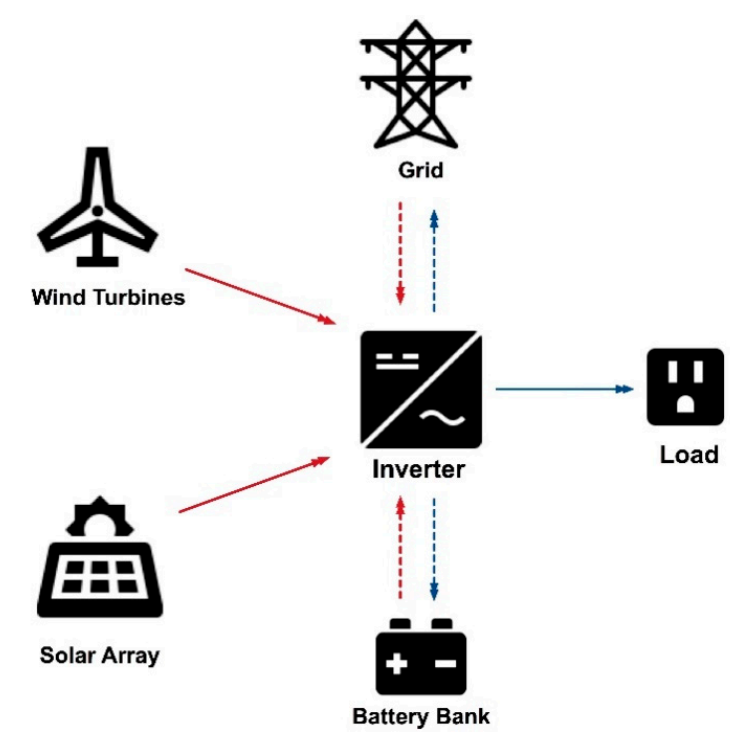

Figure 1. Schematic of the proposed hybrid system.

Given the system components, four different configurations are considered: (1) Grid-connected with storage system, (2) grid-connected with the possibility of selling surplus energy, (3) grid-connected without batteries, and (4) off-grid with a storage system. For each configuration, the energy generated by the renewable generators is prioritized given the required load power.

\section{Statistical Analysis of Random Variables}

In this work, meteorological data is collected for three years hourly. A total of 1095 data points are available to describe weather-condition seasonality. To define the work interval, a selection system initially devised to allow the user to define a parameter of statistical reliability. In this case, statistical reliability relates to the percentile that covers the chance of occurrence of a weather condition in the 
collected data. Hence, if a user sets $X$ percentage of statistical reliability, the data taken will be the percentile $(100-X)$ of the total points for each hour of the day so that the weather condition occurs in at least the $X$ percentage of the days per year. For example, Figures 2 and 3 show the 50th and 30th percentile for Hour 9 with respect to solar radiation and wind speed. Notice that the 50th represents the mean of value (a method widely used); while, the 30 th percentile covers the $70 \%$ of collected data points. Contrasting both figures, it can be observed that selecting the 30th percentile covers more data than that of the 50th one; however, in terms of design, the 30th percentile will demand more elements.
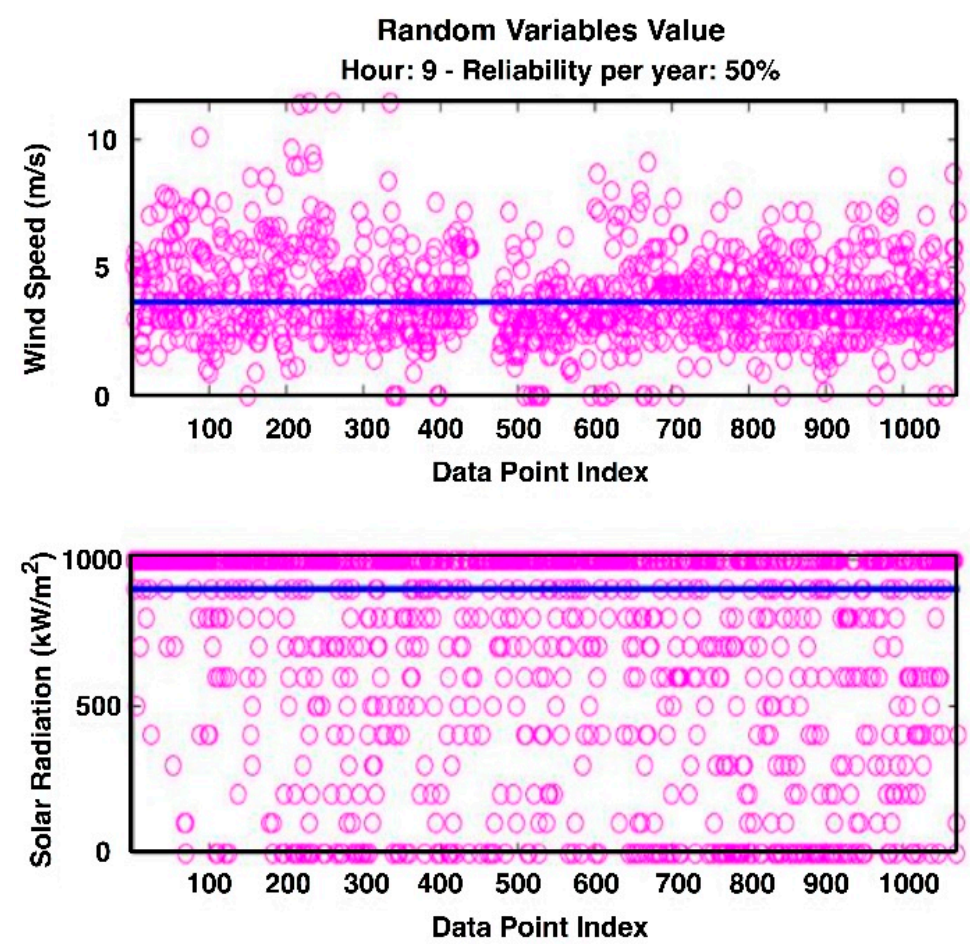

Figure 2. Selection of values with $50 \%$ of reliability.
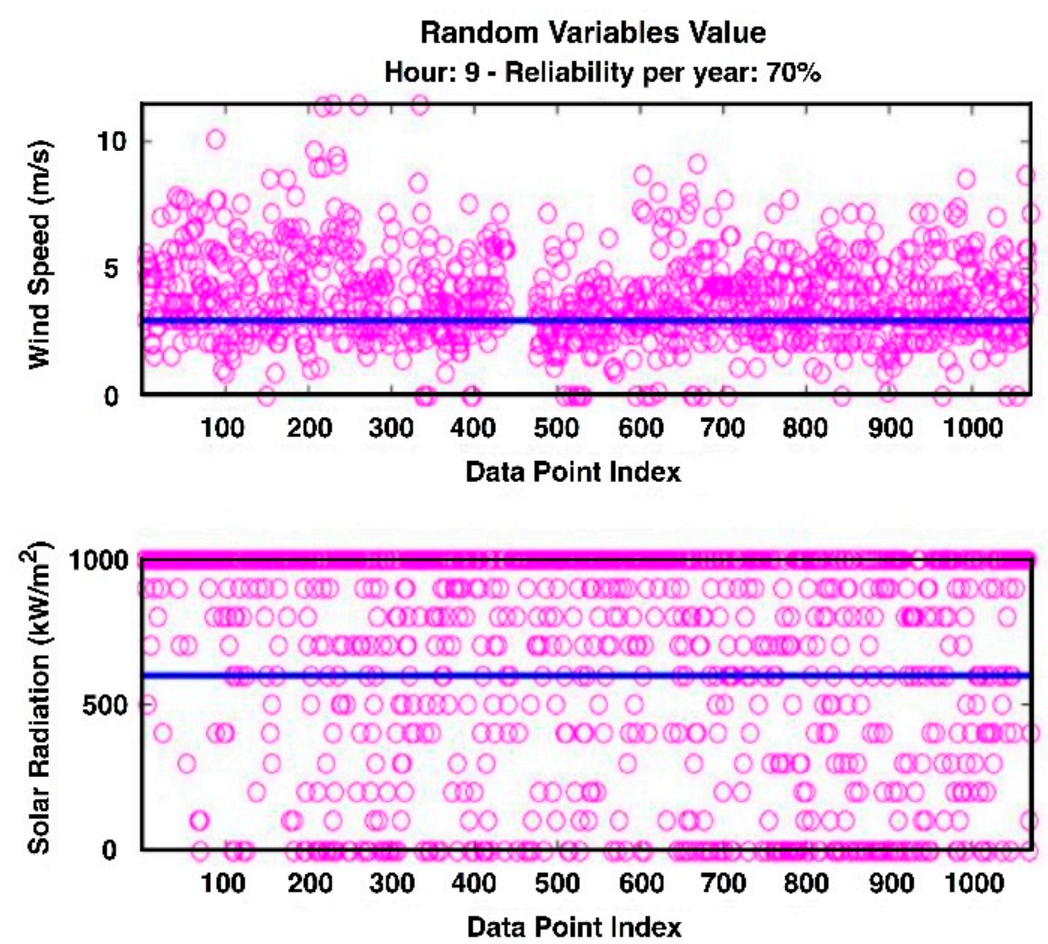

Figure 3. Selection of values with $70 \%$ of reliability. 


\section{Mathematical Models}

The selection of mathematical models of the system main components is based on what is most recommended in literature as follows.

\subsection{Solar Panel}

About 12 mathematical models for solar panels are found in the literature that are applied to solar-wind hybrid systems as shown in Table 1 [3,16-26]. For this work, the model referenced in [20-22] is selected because it covers most of the characteristics and it is employed in the majority of the consulted references.

Table 1. Studied mathematical model for solar panel.

\begin{tabular}{|c|c|c|c|c|c|c|c|c|c|}
\hline $\begin{array}{l}\text { References } \\
\text { Characteristics }\end{array}$ & {$[16,17]$} & [18] & [19] & [20-22] & [23] & [24] & [25] & [26] & [3] \\
\hline Solar radiation & $\checkmark$ & $\checkmark$ & $\checkmark$ & $\checkmark$ & $\checkmark$ & $\checkmark$ & $\checkmark$ & $\checkmark$ & $\checkmark$ \\
\hline Surface area panel number & $\checkmark$ & $\checkmark$ & & $\checkmark$ & $\checkmark$ & & $\checkmark$ & $\checkmark$ & $\checkmark$ \\
\hline Module temperature & & $\checkmark$ & $\checkmark$ & $\checkmark$ & $\checkmark$ & $\checkmark$ & & & $\checkmark$ \\
\hline Ambient temperature & & $\checkmark$ & $\checkmark$ & $\checkmark$ & $\checkmark$ & $\checkmark$ & & & $\checkmark$ \\
\hline Module efficiency & $\checkmark$ & $\checkmark$ & & & & & $\checkmark$ & $\checkmark$ & $\checkmark$ \\
\hline Fill Factor & & & & $\checkmark$ & $\checkmark$ & & & & \\
\hline Derating factor & & & $\checkmark$ & & & & & & \\
\hline Vco(stc) & & & & $\checkmark$ & $\checkmark$ & & & & \\
\hline Isc(stc) & & & & $\checkmark$ & $\checkmark$ & & & & \\
\hline NOCT & & $\checkmark$ & $\checkmark$ & $\checkmark$ & $\checkmark$ & & & & \\
\hline Nominal power & & & $\checkmark$ & & & $\checkmark$ & $\checkmark$ & & \\
\hline Others & & & & & $\checkmark$ & & $\checkmark$ & $\checkmark$ & \\
\hline
\end{tabular}

Thus, given the selected model the governing equation that describes the solar-panel generated power is:

$$
P_{s p v}=N_{p a n} * V_{o c} * I_{s c} * f f
$$

where

$$
\begin{gathered}
V_{o c}=V_{o c_{-} s t c}+k v *\left(T-T_{a m b}\right) \\
I_{s c}=\left(I_{s c_{s t c}}+k i *\left(T-T_{a m b}\right)\right) * \frac{G}{1000} \\
T=T_{a m b}+\left(\frac{N O C T-20}{800}\right) * G
\end{gathered}
$$

\subsection{Wind Turbine}

Similarly, about 12 mathematical models for wind turbines are found in literature that are applied to solar-wind hybrid systems as shown in Table 2. For this work, the model referenced in $[21,23,26]$ is selected because it covers all the characteristics and it is employed in the majority of the consulted references.

Thus, given the selected model the governing equation that describes the wind-turbine generated power given certain wind speed is:

$$
P_{w t}=\left\{\begin{array}{cc}
0 & v(t)<v_{c i} \\
P_{W T m a x} & v_{c i} \leq v(t)<v_{r a} \\
P_{r} & v_{r a} \leq v(t)<v_{c o} \\
0 & v_{c o}<v(t)
\end{array}\right.
$$

where

$$
P_{\text {WTmax }}=\frac{1}{2} r O * A * V^{3}(t) * C_{p} * n w * n m e c
$$




$$
\begin{gathered}
A=\pi * r^{2} \\
V=v *\left(\frac{H m e d}{H t}\right)
\end{gathered}
$$

Table 2. Studied mathematical model for wind turbines.

\begin{tabular}{ccccccccc}
\hline References & [16] & [17,24] & [18] & [3,19] & [20] & [21,23,26] & [25] & [27] \\
Characteristics & $\checkmark$ & $\checkmark$ & $\checkmark$ & $\checkmark$ & $\checkmark$ & $\checkmark$ & $\checkmark$ & $\checkmark$ \\
Wind speed & $\checkmark$ & & $\checkmark$ & & $\checkmark$ & $\checkmark$ & & $\checkmark$ \\
Power Coefficient & $\checkmark$ & $\checkmark$ & & $\checkmark$ & & $\checkmark$ & $\checkmark$ \\
Vci (Cut in speed) & $\checkmark$ & $\checkmark$ & & $\checkmark$ & & $\checkmark$ & $\checkmark$ \\
Vr (rated speed) & $\checkmark$ & $\checkmark$ & & $\checkmark$ & & $\checkmark$ & $\checkmark$ \\
Vco (cut off speed) & $\checkmark$ & $\checkmark$ & & & & $\checkmark$ & $\checkmark$ & $\checkmark$ \\
Generator rated power & $\checkmark$ & & $\checkmark$ & & $\checkmark$ & $\checkmark$ & $\checkmark$ & $\checkmark$ \\
Area swept & & & $\checkmark$ & & & $\checkmark$ & & $\checkmark$ \\
High relation & $\checkmark$ & & & & $\checkmark$ & $\checkmark$ & & \\
Efficiency gear box & $\checkmark$ & & & & $\checkmark$ & $\checkmark$ & $\checkmark$ \\
Turbine efficiency & & & $\checkmark$ & $\checkmark$ & & & \\
Others & & & & & & & \\
\hline
\end{tabular}

\subsection{Battery}

About 7 mathematical models for batteries are found in the literature that are applied to solar-wind hybrid systems as shown in Table 3 . For this work, the model referenced in $[3,20,27]$ is selected because it covers all the characteristics and it is employed in the majority of the consulted references.

\begin{tabular}{|c|c|c|c|c|c|}
\hline $\begin{array}{l}\text { References } \\
\text { Characteristics }\end{array}$ & [18] & {$[3,20,27]$} & [23] & {$[24]$} & [25] \\
\hline SOC before & & $\checkmark$ & $\checkmark$ & $\checkmark$ & \\
\hline SOC minimum & & $\checkmark$ & $\checkmark$ & $\checkmark$ & \\
\hline SOC maximum & & $\checkmark$ & $\checkmark$ & $\checkmark$ & \\
\hline Efficiency & & $\checkmark$ & $\checkmark$ & & $\checkmark$ \\
\hline$\sigma$ & & $\checkmark$ & & & \\
\hline Power & $\checkmark$ & $\checkmark$ & $\checkmark$ & & \\
\hline Voltage & $\checkmark$ & & $\checkmark$ & $\checkmark$ & $\checkmark$ \\
\hline Current & & & & $\checkmark$ & \\
\hline Depth of discharge & $\checkmark$ & $\checkmark$ & & & $\checkmark$ \\
\hline Others & & & & & $\checkmark$ \\
\hline
\end{tabular}

Table 3. Studied mathematical model for batteries.

The battery model is based on the SOC, which can be defined as

$$
S O C=S O C_{-} *(1-r o)+P * n_{b a t}
$$

where

$$
P=P_{G}(t)-P_{L}(t)
$$

From this definition, $P$ will be a negative value if the load exceeds the power generated by the system. At any time, the storage capacity is subject to the following constraint:

$$
S O C_{\max } * D O D \leq S O C \leq S O C_{\max }
$$

\section{System Optimization and Programming}

A GA is selected as optimization technique to dimension the hybrid renewable energy system, because of its adaptability to solve problems with multiple solutions. In this work, optimization seeks 
to determine the optimal number of solar panels, wind turbines, and batteries (if available). In addition, depending on the case study and user needs, optimization can also determine the optimal solar panel, wind turbine, and battery (brand and model) which means that the variables in the objective function could change from two to six variables.

MATLAB is selected to implement the design methodology with GA and GAMultiobjective tools. The GA toolbox finds the minimum value of a function with only one fitting function using GA. This tool handles a row vector of numbers whose length equals the number of variables, it also accepts integer values as variables in the objective function, but it cannot use linear-equality constraints when integer values are required. With respect to the GAMultiobjective toolbox, it finds the minimum value of a function with two fitting functions using GA, this tool also handles a row vector of numbers whose length equals the number of variables; however, it does not accept integer values as variables, which imposes editing the main GAMultiobjective algorithm. The output of the GAMultiobjective tool is a Pareto Front for the fitting functions.

Furthermore, a study is carried out to explore the optimization approaches used to optimally size hybrid solar-wind renewable energy systems. Despite a large number of optimization approaches found in literature, four optimization approaches are selected and explained below.

\subsection{Loss of Power Supply Probability (LPSP)}

It refers to the power that cannot be supplied to the total demand. Thus, this approach seeks to have a $0 \%$ LPSP. Mathematically, it is expressed as

$$
\text { LPSP }=\frac{\sum_{1}^{24} \text { power supplied }- \text { load power }}{\text { load power }} * 100
$$

\subsection{Initial Capital Cost (ICC)}

It refers to the initial investment made by the user to acquire the system elements. Hence, the ICC is intended to be minimized, which indicates that the system investment is as little as possible following the design restrictions. The ICC is mathematically represented as

$$
\text { Initial cost }=C_{\text {pan }} * N_{\text {pan }}+C_{w t} * N_{w t}+C_{b a t} * N_{b a t}+C_{i n v}
$$

\subsection{Life Cycle Cost (LCC)}

It refers to the total cost of the system during its lifetime. For the LCC, element initial cost, each element life cycle and that of its replacement (in case of being less than the system life cycle), operation, and maintenance are considered. The LCC is mathematically expressed as

$$
L C C=C_{l p}+C_{l w}+C_{l b}+C_{l i n v}
$$

where

$$
\begin{gathered}
C_{l p}=C_{s 1}+C_{s 2}, \\
C_{s 1}=C_{p a n}+N_{p a n}, \\
C_{s 2}=\alpha_{p o \& m} * N_{p a n} * \sum_{k=1}^{N_{y}}\left(\frac{1+\varepsilon_{p v}}{1+r}\right)^{k}, \\
C_{l w}=C_{w 1}+C_{w 2}, \\
C_{w 1}=C w * N w * \sum_{x=1}^{X_{w}}\left(\frac{1+\varepsilon_{w}}{1+r}\right)^{(x-1) l_{w},} \\
C_{w 1}=\alpha_{w o \& m} * N p * \sum_{1}^{N_{y}}\left(\frac{1+\varepsilon_{w}}{1+r}\right)^{k},
\end{gathered}
$$




$$
\begin{aligned}
& C_{l b}=C_{b a t} * N_{b a t} * \sum_{1}^{X_{b}}\left(\frac{1+\varepsilon_{b}}{1+r}\right)^{(x-1) l_{b},} \\
& C_{\text {lin }}=C_{i n v} * \sum_{1}^{X_{i n v}}\left(\frac{1+\varepsilon_{\text {inv }}}{1+r}\right)^{(x-1) l_{\text {inv }},}
\end{aligned}
$$

\subsection{Loss of Power Supply (LPS)}

It refers to the day hours when the load power is not supplied entirely by the renewable system. Thus, the ideal LPS is $0 \%$. The LPS is mathematically expressed as

$$
L P S=\frac{\sum_{1}^{24}(\text { power supplied }<\text { load power } \geq 1)}{24} * 100
$$

As commented there are four different possible systems. The programming of each configuration is different due to the specific elements and restrictions; however, all configurations design is based on the same target, prioritize the use of renewable energy generation. For the general system operation, different variables are defined for power values. Thus, the following code is run,

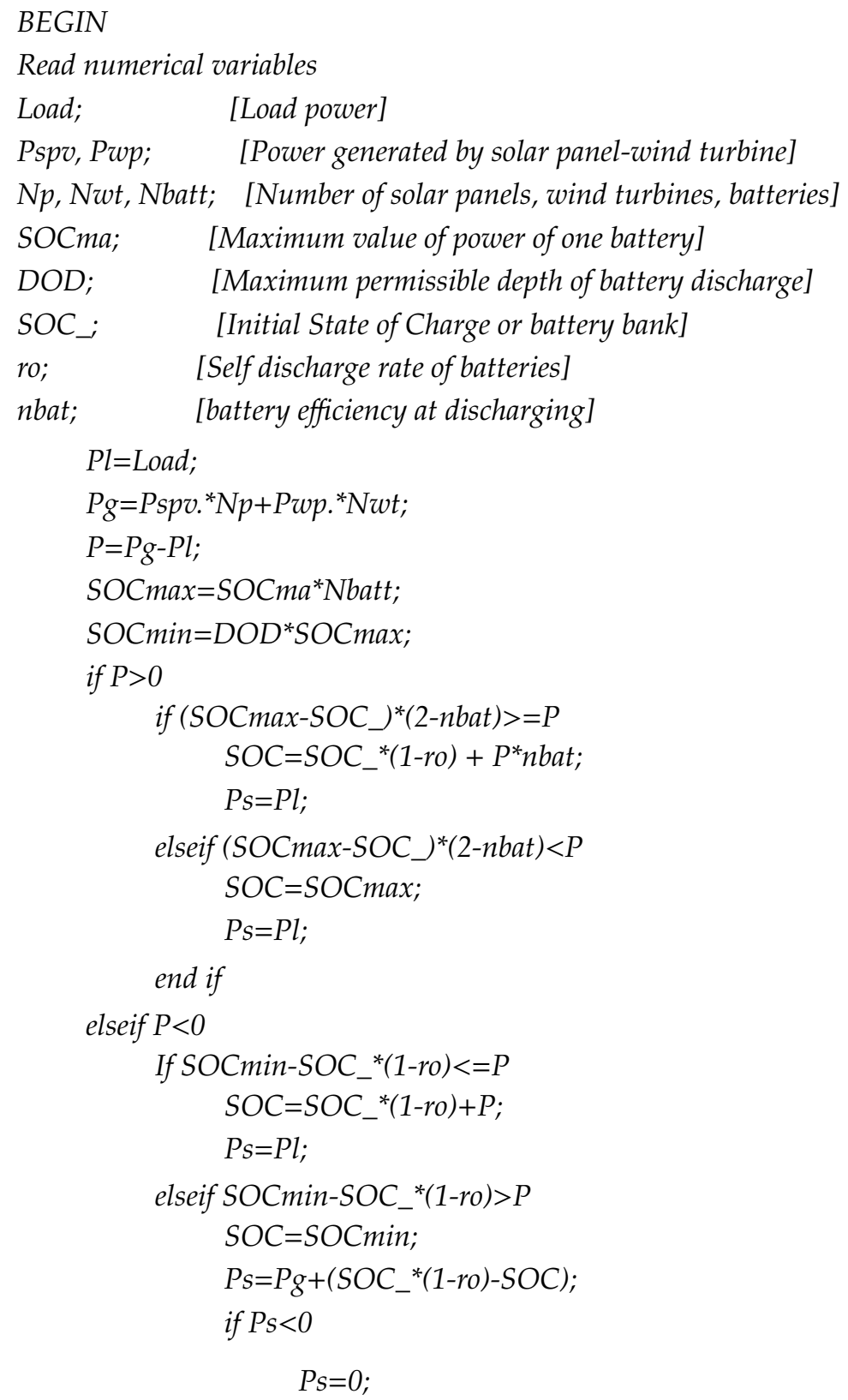




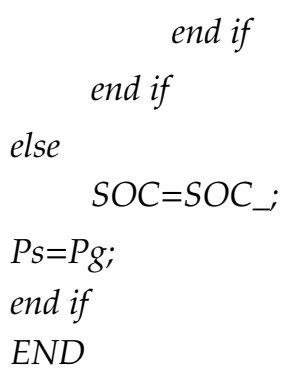

This process is repeated for the $24 \mathrm{~h}$ of a day. To know the initial power of the storage system, the process is repeated for another $24-\mathrm{h}$ period considering the last batteries SOC. If no storage system is available, the process is the same but assuming that the SOC is always zero and the batteries cannot be completely charged.

\section{Economic Analysis}

The economic analysis seeks to give information not only about the system initial and life cycle costs, but also the investment recovery time. As defined, ICC and LCC can be calculated using Equations (5) and (6), respectively; while for the investment recovery time, a flowchart concept is used to visualize how the investment flows through time. The system analysis is performed annually as shown in Figure 4. In this figure, ICC corresponds to the system initial cost value, AE is the generated annual profits, $\mathrm{O} \& \mathrm{M}$ is the yearly system operation and maintenance costs, $\mathrm{RCB}$ corresponds to the battery replacement cost required to have a lifetime of $X$ years, and RCW equals the wind-turbine replacement cost set to $X+1$ life cycle years. For this example, the system lifetime is assumed to be $2 X$ +3 and the solar-panel life cycle is expected to be equal to or greater than this value.

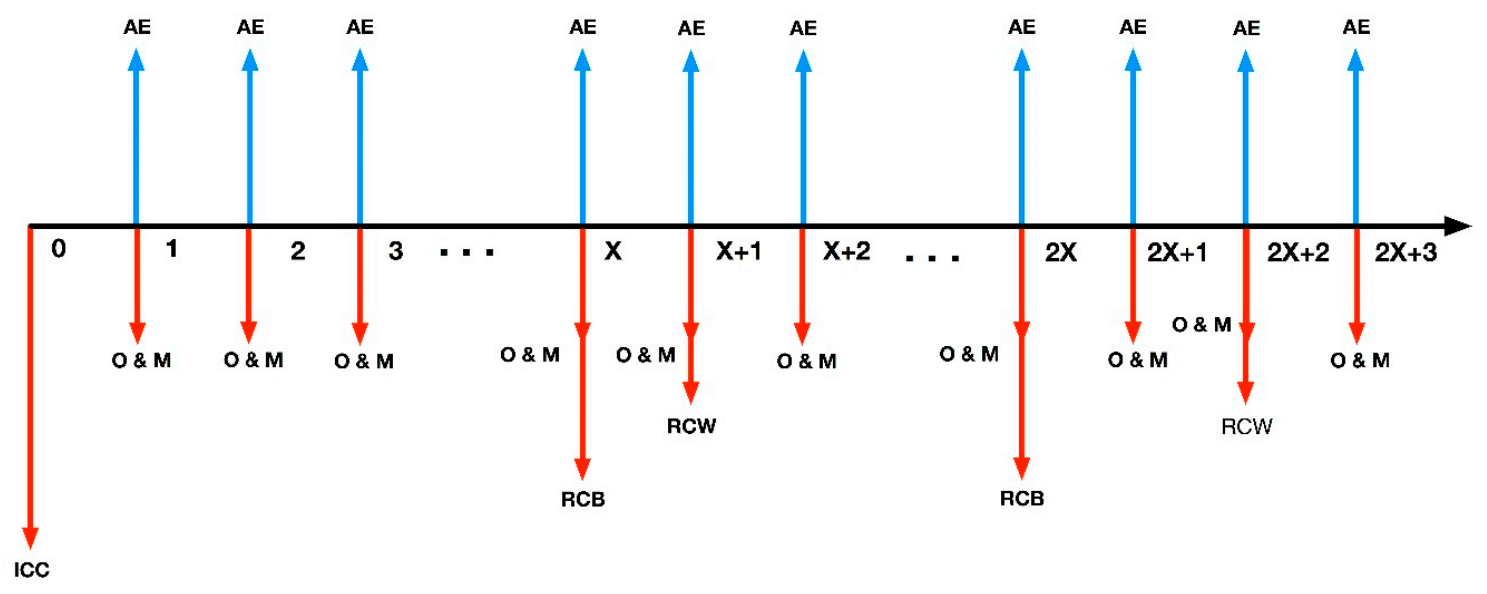

Figure 4. System life cycle flowchart.

The AE is calculated using Equation (8). The expression is based on the savings in $\mathrm{kWh}$ from the grid due to the power supplied by the renewable generators on the days, in which the system reliability can be statistically assured,

$$
A E=\sum_{1}^{24} \frac{\text { Power supplied by system }\left(P_{S}\right)}{1000} \times\left(365 \times \frac{\text { Reliability per year }}{100} \times \text { Price } k W h\right)
$$

Thus, the flowchart is used to calculate the years for the return on investment. For this purpose, all future values are taken to present value, and the yearly outputs are taken to obtain a NPV equal or less than zero. 


\section{Developed Computational Tool: HYRES}

The MATLAB Graphical User Interface (GUI) application is used to implement a custom-made computational tool for feasible and user-friendly system sizing optimization called Hybrid Renewable Energy System (HYRES) [28].

Initially, HYRES offers the user the option of selecting between two different currencies, Colombian Pesos (COP) and American Dollars (USD), as shown in Figure 5. Then, the GUI pops the system sizing interface up as shown in Figure 6.

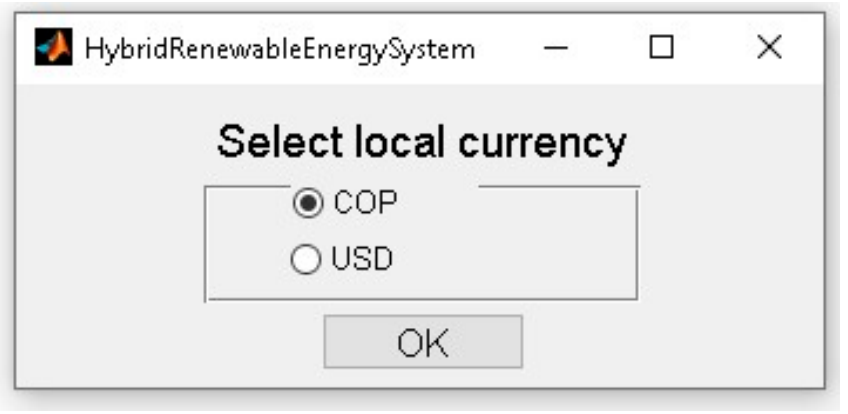

Figure 5. Selection of local currency in the developed system.

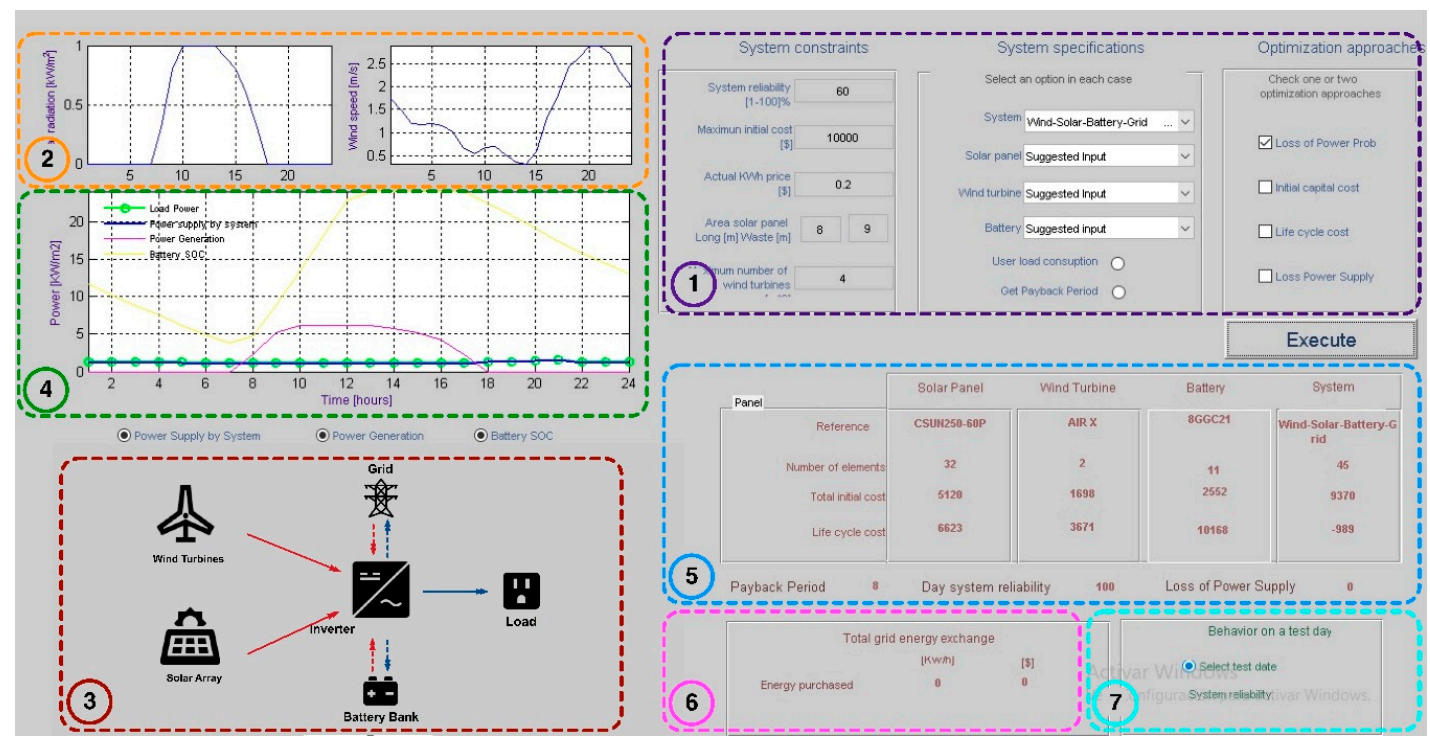

Figure 6. Hybrid Renewable Energy System (HYRES) interface.

Figure 6 shows that the sizing interface can be divided into five boxes. Box 1 refers to the system inputs. Here, there are three blocks: System constraints, System specifications, and Optimization approaches. First, System constraints refer to system restrictions. For that, the minimum reliability values in a $25-75 \%$ range is recommended, since values outside this range are considered isolated data. Then, the user enters the maximum initial cost that can afford for the system. It is important to note that according to the entered specifications, the restrictions can be in conflict with each other producing a void design. For example, a user can request to have a $70 \%$ of system reliability during the year with only $\$ 100$ USD. Then, the kWh cost from the network operator is required to carry out energy purchase and sale, if possible. Finally, the available area for solar-panel placement, as well as the maximum amount of wind turbines are requested.

Then for the System specifications part, the GUI offers a list of four possible options for system implementation: 1. Wind-solar-battery-grid, 2. Wind-solar-grid-sale excess, 3. Wind-solar-battery and 4. Wind-solar-grid. Once the user has chosen the preferred configuration option, the solar panel, wind 
turbine, and battery references (brand and model) can be selected. In this case, there are three possible options: Suggested input, which indicates to the software to select the most suitable reference to use; Manual input, which prompts the user to enter the data of his/her selected reference; and Select an input, when the user can choose a reference from a list of stored references saved previously. These stored references are the ones used by the software if Suggested input is chosen.

After these options, the User Load Consumption button allows the user to upload the load data during a typical day of consumption ( $24 \mathrm{~h}$ interval). Next, the Get Payback Period button lets the user enter the interest rates that apply, as well as the operation and maintenance rates of solar panels, wind turbines, and batteries. This information is used by HYRES to calculate the payback period in years.

Finally, for the Optimization approaches, the user has the possibility to select one or two optimization approaches to properly size the system components. As mentioned, the available options are LPSP, ICC, LCC, and LPS.

Then, Box 2 shows the selected values of solar radiation and wind speed according to the selected reliability. Those are displayed in a $24 \mathrm{~h}$ interval and are expressed in $\mathrm{kW} / \mathrm{m}^{2}$ and $\mathrm{m} / \mathrm{s}$, respectively. Box 3 shows the system components and power flow according to user selection. Box 4 displays the system behavior given the selected values/configurations. The green line is the load profile entered by the user; the blue line, is the power delivered to the load; the magenta line shows the electric power available from the solar and wind sources per hour; and finally, the yellow line shows the battery behavior. Box 4 allows the user to enable or disable lines to clarify the plot, if needed. Box 5 shows the reference, quantity, initial cost and life cycle cost of each element along to the total elements. Below that reports, HYRES presents the Payback period of the system in years, the reliability per day, and the loss of power supply value. Box 6 shows energy purchase and sale daily values in $\mathrm{kWh}$ and cost of these transactions, if enabled. Finally, Box 7 allows running a test with a specific day of the year selected.

Once the user starts HYRES, a window appears showing the optimization process and partial results, which can be plotted for the user. Figure 7 shows the popup window for a mono-objective optimization, and Figure 8 shows the process for a multi-objective optimization.

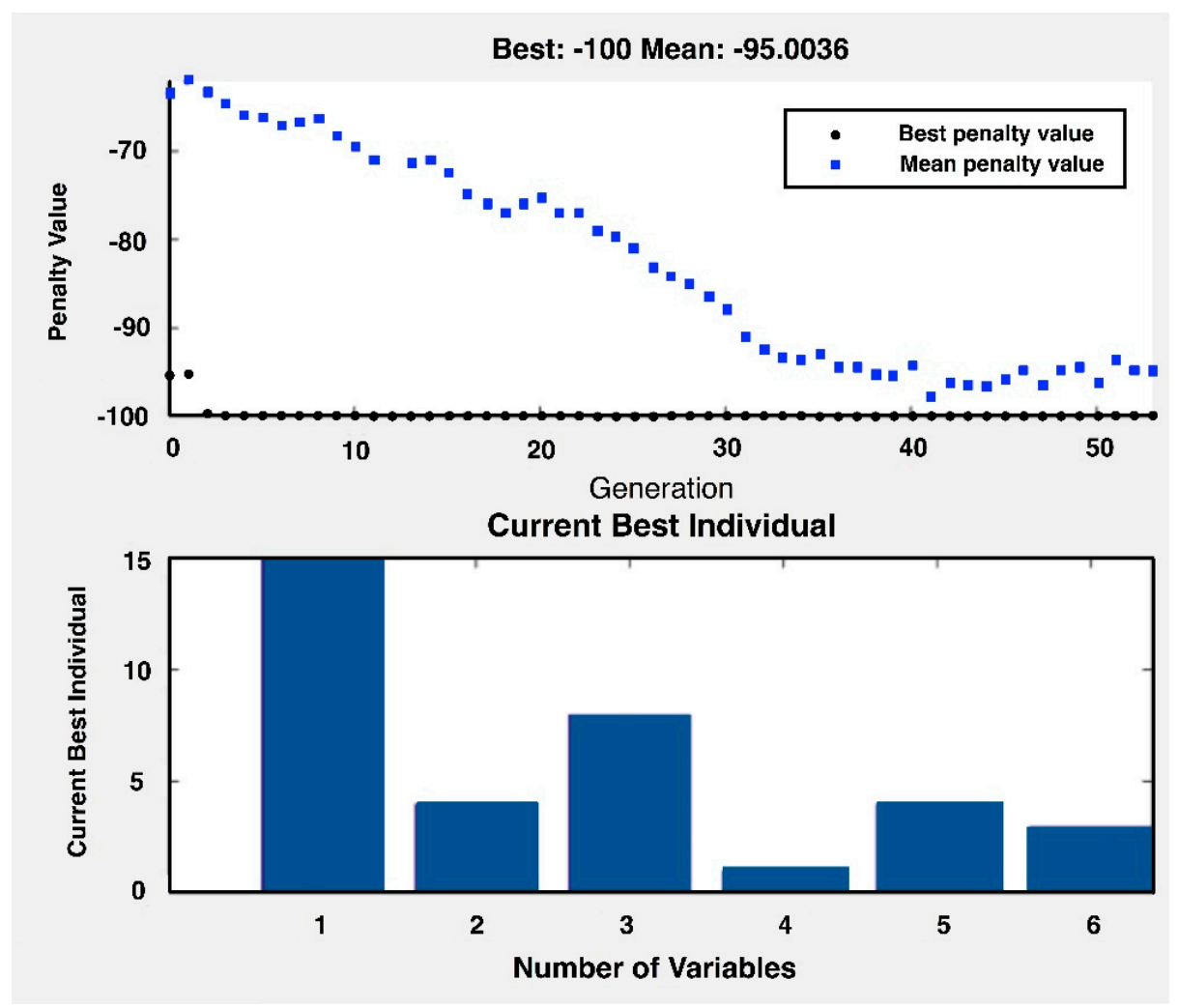

Figure 7. Interactive window showing the convergence for mono-objective optimization. 


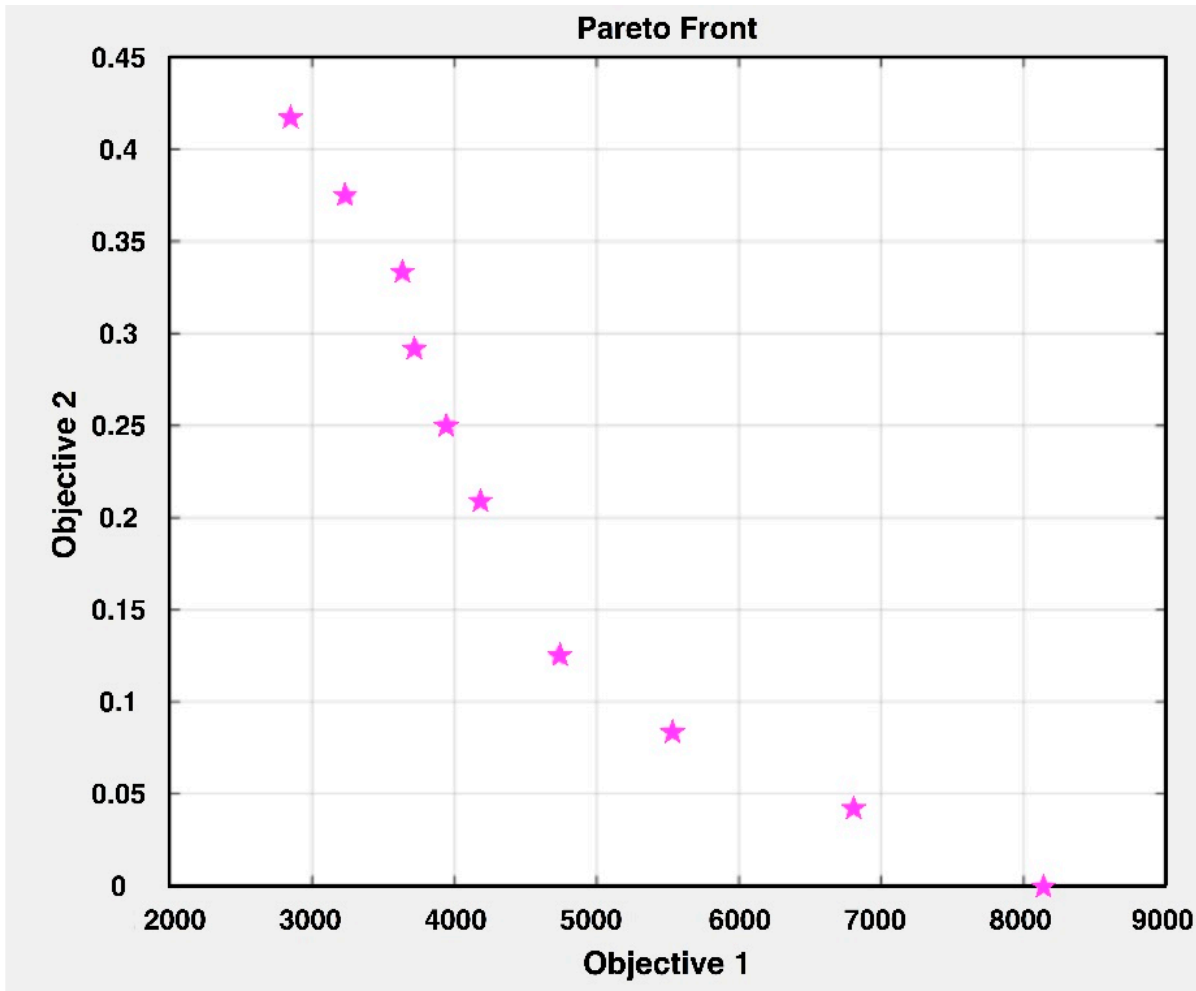

Figure 8. Interactive window showing the convergence for multi-objective optimization.

\section{Results and Discussion}

A set of experiments is established to verify the utility, feasibility, and reliability of the results produced by HYRES with respect to the ones obtained with the commercial software HOMER for different case studies. Here, it is important to emphasize that HOMER has the particularity of minimizing the system NPV in every optimization case. In addition, other variables of HYRES cannot be modified in HOMER, such as the optimization of the element references and the initial maximum cost.

Consequently, the following characteristics are defined for the set of experiments:

Variant Factors:

1. Reliability: establishes the annual system reliability with values of $50 \%$ and $75 \%$.

2. Location: three different locations are defined: Miami-USA, Barranquilla-Colombia, and Fortaleza-Brazil. The three locations are due to data availability, different climate conditions, and time zones.

3. User demand: Two user demands are selected and the differences are in the demand curve and daily consumption. The selected demand profiles are taken from [29]. The profiles are presented in Figures 9 and 10.

4. System configuration: Configuration 1: Solar PV—Wind Turbines-Batteries-Grid connection (no possibility of selling energy to grid) and Configuration 2: Solar PV—Wind Turbines-Grid connection (possibility of selling energy to grid) of the system are selected.

Constant Factors:

- Currency: USD

- $\quad$ Maximum initial cost: $\$ 15,000$

- $\quad$ kWh Cost: $\$ 0.2$

- Solar Area Panel: $72 \mathrm{~m}^{2}-37$ panels-11.8 kW 
- $\quad$ Number of Wind turbines: 4

- Interest rate per year: $4.95 \%$

- O\&M cost of solar panels: $\$ 10$

- O\&M cost of wind turbines: \$30

- O\&M cost of batteries: $\$ 10$

- Optimization approach: NPV

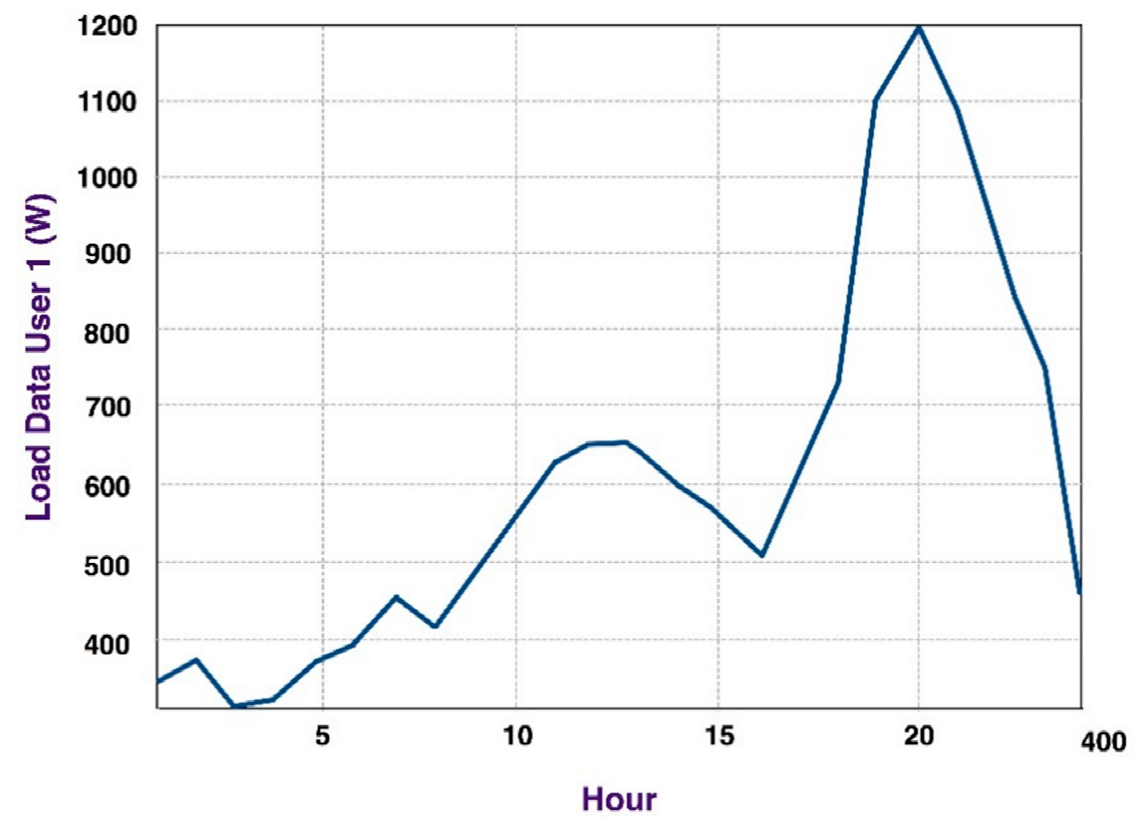

Figure 9. Load demand of User 1.

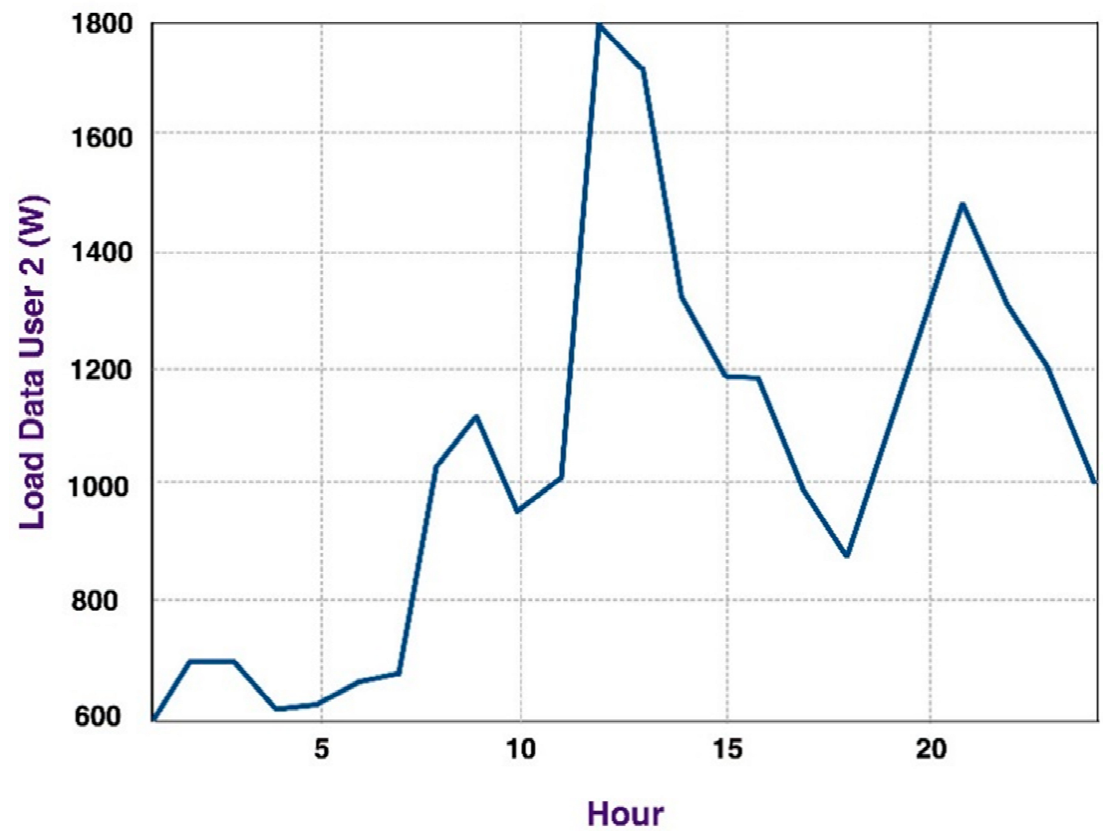

Figure 10. Load demand of User 2.

The results obtained with HOMER and HYRES for each of the case are presented in Table 4 . 
Table 4. Results obtained from HOMER and HYRES

\begin{tabular}{|c|c|c|c|c|c|c|c|c|c|c|c|c|}
\hline \multirow{2}{*}{ CASE } & \multirow{2}{*}{ Config } & \multirow{2}{*}{ Location } & \multirow{2}{*}{ User } & \multirow{2}{*}{ Reliab. (\%) } & \multicolumn{4}{|c|}{ HOMER } & \multicolumn{4}{|c|}{ HYRES } \\
\hline & & & & & ICC \$ & NPC US\$ & RF \% & P-WT-B & ICC \$ & NPC US\$ & RF \% & P-WT-B \\
\hline Case1 & Config. 1 & Miami & User 1 & 50 & 2507 & 11,254 & 50 & $2.56-0-3$ & 2236 & 11,720 & 51 & $8-0-3$ \\
\hline Case2 & Config. 1 & Miami & User 1 & 75 & 4774 & 11,409 & 76 & $3.31-0-8$ & 4583 & 10,916 & 77 & $12-0-3$ \\
\hline Case3 & Config. 1 & Miami & User 2 & 50 & 3810 & 17,726 & 52 & $3.98-0-3$ & 3560 & 18,342 & 50 & $14-0-1$ \\
\hline Case4 & Config. 1 & Miami & User 2 & 75 & 7359 & 17,918 & 76 & $5.63-0$ & 7347 & 17,946 & 77 & $20-0-9$ \\
\hline Case5 & Config. 1 & Bquilla & User 1 & 50 & 4739 & 8577 & 98 & $2.46-0-10$ & 4858 & 8541 & 100 & $7-0-11$ \\
\hline Case6 & Config. 1 & Bquilla & User 1 & 75 & 4739 & 8577 & 98 & $2.46-0-10$ & 4858 & 8541 & 100 & $7-0-11$ \\
\hline Case7 & Config. 1 & Bquilla & User 2 & 50 & 7170 & 12,980 & 97 & $4.19-0-14$ & 6968 & 12,570 & 98 & $11-0-15$ \\
\hline Case8 & Config. 1 & Bquilla & User 2 & 75 & 7170 & 12,980 & 97 & 4.19-0-14 & 6968 & 12,570 & 98 & $11-0-15$ \\
\hline Case9 & Config. 1 & Fortaleza & User 1 & 50 & 4124 & 7796 & 93 & $1.31-2-5$ & 3099 & 6166 & 100 & $1-2-4$ \\
\hline Case10 & Config. 1 & Fortaleza & User 1 & 75 & 4124 & 7796 & 93 & $1.31-2-5$ & 3099 & 6166 & 100 & $1-2-4$ \\
\hline Case11 & Config. 1 & Fortaleza & User 2 & 50 & 5175 & 19,358 & 53 & 3.16-3-1 & 5088 & 10,261 & 100 & $1-4-5$ \\
\hline Case12 & Config. 1 & Fortaleza & User 2 & 75 & 9587 & 20,771 & 75 & $5.62-4-7$ & 5088 & 10,261 & 100 & $1-4-5$ \\
\hline Case13 & Config. 2 & Miami & User 1 & 50 & 8746 & $-29,341$ & 87 & $8.75-0-0$ & 8743 & $-15,728$ & 85 & $37-0-0$ \\
\hline Case14 & Config. 2 & Miami & User 1 & 75 & 8746 & $-29,341$ & 87 & $11.8-0-0$ & 8743 & $-15,728$ & 85 & $37-0-0$ \\
\hline Case15 & Config. 2 & Miami & User 2 & 50 & 8746 & $-18,433$ & 81 & $11.8-0-0$ & 8743 & $-12,322$ & 78.7 & $37-0-0$ \\
\hline Case16 & Config. 2 & Miami & User 2 & 75 & 8746 & $-18,433$ & 81 & $11.8-0-0$ & 8743 & $-12,322$ & 78.7 & $37-0-0$ \\
\hline Case17 & Config. 2 & Bquilla & User 1 & 50 & 8746 & $-47,532$ & 90 & $11.8-0-0$ & 8743 & $-65,279$ & 92.5 & $37-0-0$ \\
\hline Case18 & Config. 2 & Bquilla & User 1 & 75 & 8746 & $-47,532$ & 90 & $11.8-0-0$ & 8743 & $-65,279$ & 92.5 & $37-0-0$ \\
\hline Case19 & Config. 2 & Bquilla & User 2 & 50 & 8746 & $-36,623$ & 86 & $11.8-0-0$ & 8743 & $-50,241$ & 87 & $37-0-0$ \\
\hline Case20 & Config. 2 & Bquilla & User 2 & 75 & 8746 & $-36,623$ & 86 & $11.8-0-0$ & 8743 & $-50,241$ & 87 & $37-0-0$ \\
\hline Case21 & Config. 2 & Fortaleza & User 1 & 50 & 12,142 & $-34,482$ & 100 & $11.8-0-0$ & 12,139 & $-52,282$ & 100 & $37-0-0$ \\
\hline Case22 & Config. 2 & Fortaleza & User 1 & 75 & 12,142 & $-34,482$ & 100 & $11.8-0-0$ & 12,139 & $-52,282$ & 100 & $37-0-0$ \\
\hline Case23 & Config. 2 & Fortaleza & User 2 & 50 & 12,142 & $-23,573$ & 92 & $11.8-0-0$ & 12,139 & $-40,867$ & 94 & $37-0-0$ \\
\hline Case24 & Config. 2 & Fortaleza & User 2 & 75 & 12,142 & $-23,573$ & 92 & $11.8-0-0$ & 12,139 & $-40,867$ & 94 & $37-0-0$ \\
\hline
\end{tabular}


For the rows orange shaded, the experiment show cases with equal variant factors except for the required reliability, which changes from $50 \%$ to $75 \%$. Thus, when making the comparison between both systems for this change of reliability, it can be observed that there are many similarities in the results, such as the ICC, whose ratio for Case 1 and 2 equals 1.9 and 2.0 for HOMER and HYRES, respectively. However, there is a change in the Net Present Cost (NPC), where HOMER increases from Case 1 to Case 2, while HYRES decreases.

For the rows green shaded, the experiment changes the system location (city). The first city, Barranquilla has good values of solar radiation and low values of wind speed; while the second city, Fortaleza, exhibits high-speed values for wind and average values of solar radiation. The results show that both systems are adjusted to these climatic conditions, prioritizing wind energy in case of Fortaleza, and solar energy in the case of Barranquilla.

For the rows blue shaded, there is a change in the load consumption, besides the type of system selected and by the possibility of energy sale to the grid. In this case, both systems maximize the use of renewable energies to obtain the highest profitability in energy sales. It is interesting to observe from the results that is not possible to deliver the same amount of renewable energy in both loads, mainly due to the demand in hours where there is no generation and the absence of a storage system.

Finally, for the rows red shaded, there is a change in the system configuration. The results show that although in Configuration 2, the renewable generation sets its limit to have benefits from the energy sale to the grid, Configuration 1 limits the use of renewable energy to meet user requirements.

From the obtained results with HOMER and HYRES, it is possible to perform a statistical analysis to determine the relationship between them. Thus, variance analysis is carried out to compare initially the means, followed by a multivariate test. These processes are performed using the MATLAB anovan and multcompare toolbox. Analysis of variance compares the means of several groups to test the hypothesis that they are all equal, against the general alternative that they are not all equal. After the analysis of variance, a test that allows identifying which means are different and furthermore carries out a comparison between a means group is necessary to implement. In this project is used multiple comparison test named Tukey-Kramer to identify the means significantly different. When there are many groups, there are many pairs to compare. If an ordinary t-test is applied in this situation, the alpha value would apply to each comparison, so the chance of incorrectly finding a significant difference would increase with the number of comparisons. Multiple comparison procedures are designed to provide an upper bound on the probability that any comparison will be incorrectly found significant.

Figures 11-13 summarize the results for Initial Capital Cost (ICC), Net Present Cost (NPC), and Renewable Fraction (RF). Thus, from the previous figures, it is possible to observe that there is no statistical difference between the results reported by the two software; therefore, it is possible to verify the reliability of the implemented system with a commercial system, worldwide leader in microgrid modeling. It is important to note that HOMER only provides parameter optimization under the NPC, in addition of having no initial cost restrictions. Another significant difference is that the number of solar panels in HOMER is not an integer value and the optimization is done according to areas and powers parameters, while HYRES performs the optimization based on the number of solar modules.

According to Figures 14-16, it is possible to observe that in cases associated with costs like ICC, the multi-objective approach presents a statistically mean significantly lower than the mono-objective approach; while, for the efficiency case, it is shown that the mean is not significantly different. Now for the payback-years mean, it is higher in mono-objective optimization; therefore, it can be affirmed that the multi-objective optimization has a better cost-benefit ratio than the mono-objective optimization. In addition, a significant advantage of HYRES is that presents the possibility of performing multi-objective optimizations that have shown a better performance than the mono-objective optimization used in several commercial systems like HOMER. 


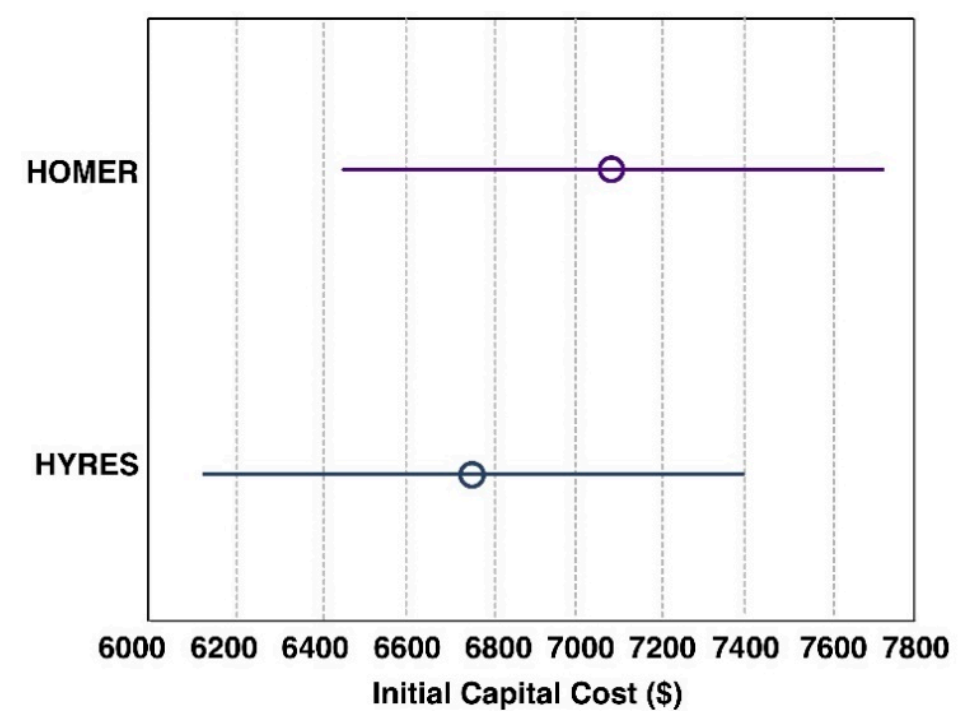

Figure 11. Multiple comparison test of Initial Capital Cost (ICC).

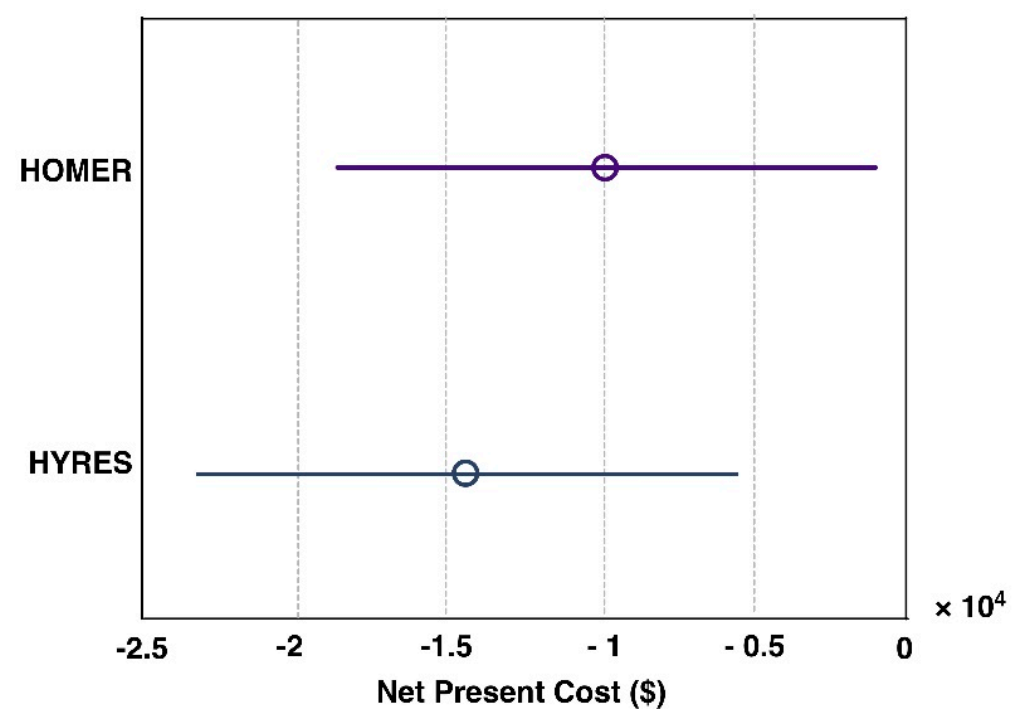

Figure 12. Multiple comparison test of Net Present Cost (NPC).

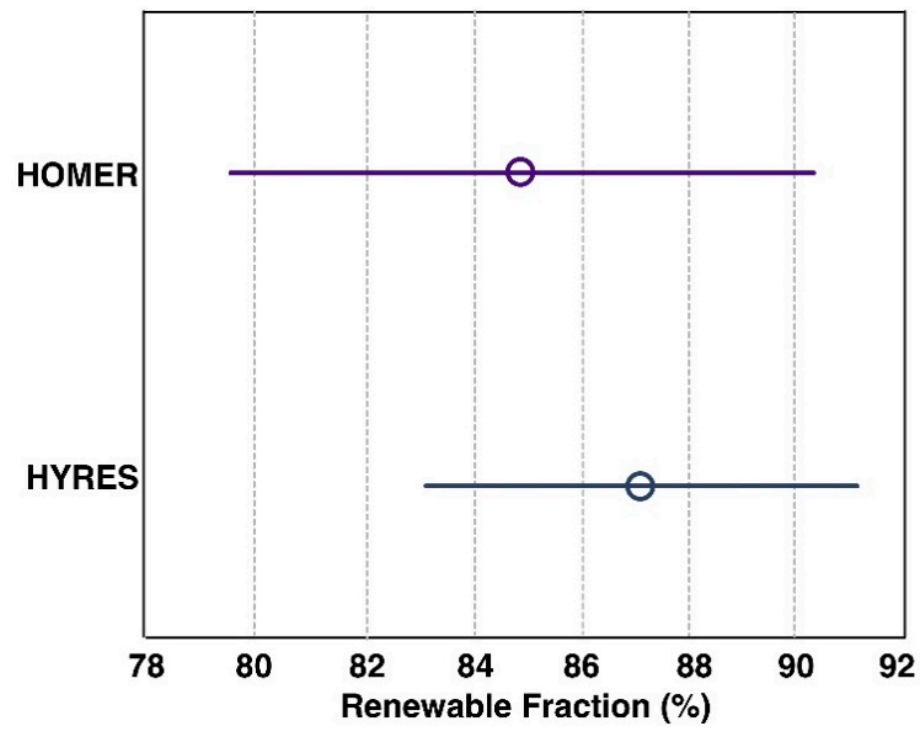

Figure 13. Multiple comparison test of Renewable Fraction (RF). 


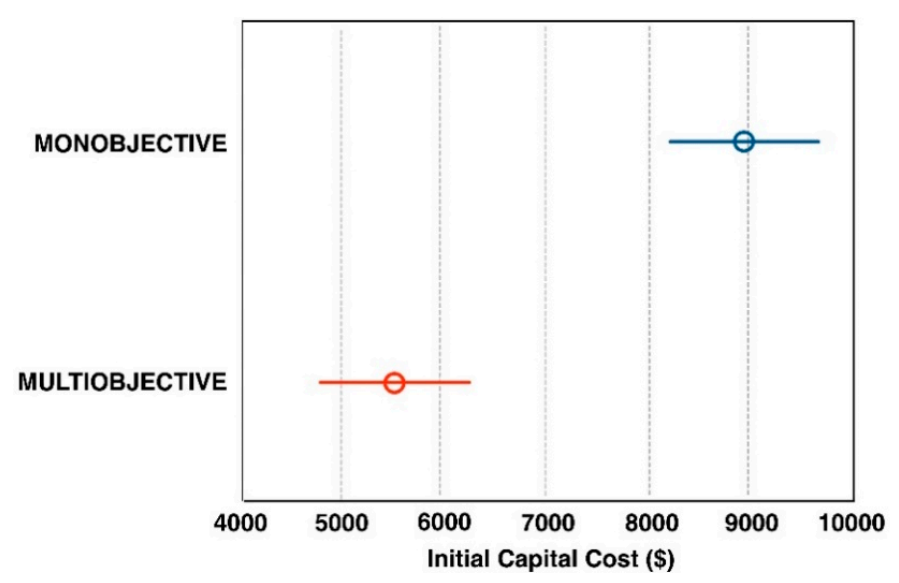

Figure 14. Multiple comparison test of ICC.

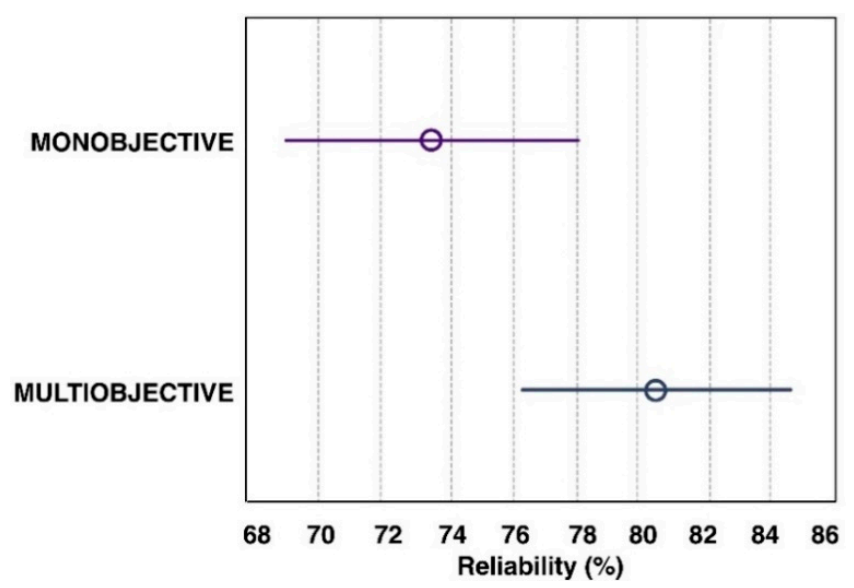

Figure 15. Multiple comparison test of Reliability.

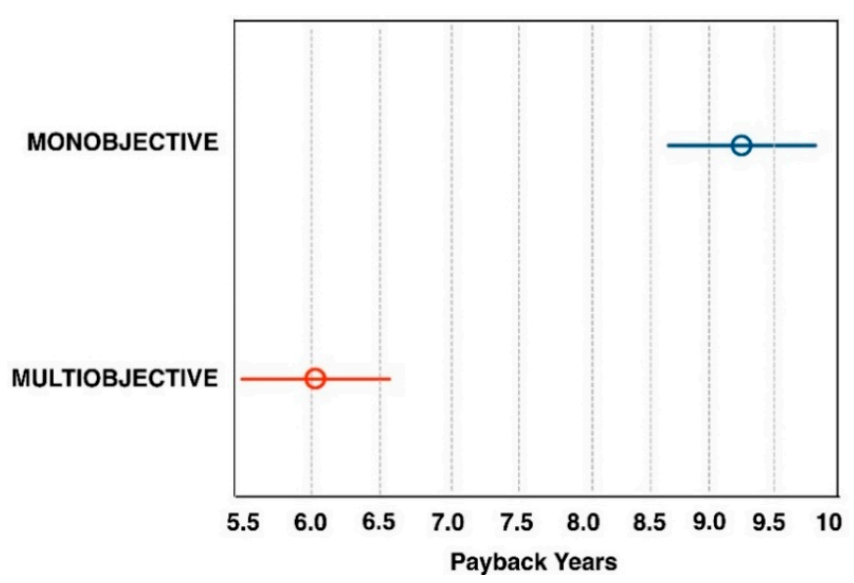

Figure 16. Multiple comparison test of Payback years.

\section{Conclusions and Future Work}

This paper presents a system oriented to dimensioning hybrid renewable energy systems with solar photovoltaic and wind resources. The proposed system contributes with powerful tools to perform the optimization of renewable hybrid systems, through the use of genetic algorithms, which as shown, are algorithms highly used for this type of study due to their adaptive properties. The results analysis for the different case studies where the system is tested show that it has properties of utility, viability, and reliability. As shown, HYRES is a powerful tool to contribute in the viability analysis of energy systems involving renewable generators. When a system has a variety of design possibilities, 
HYRES becomes attractive as it allows various input parameters related to climatic conditions, statistical reliability, and economic views.

The comparisons made with HOMER show that HYRES is statistically acceptable; however, HYRES offers additional features that make it more viable to explore different scenarios of a case study. Such features include; first, the possibility to make multi-objective optimization using GAs; and second, the system adaptability in terms of restrictions like initial capital cost, minimum reliability, maximum area available for solar panels, and number of wind turbines.

Even though different aspects of renewable systems are considered in HYRES; some aspects still can be improved such as optimization approach regarding environmental features as $\mathrm{CO}_{2}$ emissions, element life cycle depending on usage and environmental conditions, load prioritization and management when the grid is not available (for the associated configurations), the inclusion of other elements such as charge controllers, battery chargers and insulation transformers, and considering other renewable energy systems or additional sources as generators.

Author Contributions: Conceptualization, K.D.; data curation, K.D.; formal analysis, K.D.; investigation, K.D. and C.G.Q.M.; methodology, K.D. and C.G.Q.M.; project administration, C.G.Q.M.; software, K.D.; supervision, C.G.Q.M. and M.P.; validation, K.D., L.N., C.G.Q.M., and M.P.; visualization, L.N., C.G.Q.M., and M.P.; writing — original draft, K.D., L.N., C.G.Q.M., and M.P.; writing—review and editing, L.N., C.G.Q.M., and M.P. All authors have read and agreed to the published version of the manuscript.

Funding: This research received no external funding.

Conflicts of Interest: The authors declare no conflict of interest.

\section{Nomenclature}

\begin{tabular}{|c|c|}
\hline Npan & number of panels \\
\hline Voc & open circuit voltage \\
\hline Isc & short circuit current \\
\hline$f f$ & fill factor \\
\hline Voc_stc & open voltage under standard test conditions \\
\hline Isc_stc & short circuit under standard test conditions \\
\hline$k v$ & open voltage coefficient \\
\hline$k i$ & short circuit current coefficient \\
\hline$T$ & standard temperature \\
\hline G & global solar radiation $\left(\mathrm{W} / \mathrm{m}^{2}\right)$ \\
\hline Tamb & ambient temperature $\left(^{\circ}\right)$ \\
\hline NOCT & Nominal Operating Cell Temperature \\
\hline Pwt & power output of the wind turbine \\
\hline Pwtmax & max. available output wind turbine power \\
\hline $\operatorname{Pr}$ & nominal power generation \\
\hline ro & air density \\
\hline$v$ & wind speed \\
\hline$C p$ & efficiency of wind turbine \\
\hline Nmec & mechanical components efficiency \\
\hline$A$ & area swept by the blades of the turbine \\
\hline$r$ & radio of blades \\
\hline$V$ & wind speed at reference data \\
\hline Hmed & height of wind speed measurement \\
\hline$H t$ & height of wind speed \\
\hline$V c i$ & wind speed cut in \\
\hline Vra & wind speed rated power \\
\hline Vco & wind speed cut out \\
\hline $\mathrm{SOC}_{-}$ & initial value of the battery \\
\hline$S O C_{\max }$ & maximum power of the battery \\
\hline$D O D$ & maximum permissible depth of battery \\
\hline
\end{tabular}




$\begin{array}{ll}P & \text { battery power, } \\ \text { Ro } & \text { self-discharging rate } \\ \text { nbat } & \text { battery bank efficiency at charging state } \\ \text { Cpan } & \text { cost of each solar panel } \\ \text { Npan } & \text { number of solar panels } \\ \text { Cwt } & \text { cost of each wind turbine } \\ \text { Nwt } & \text { number of wind turbines } \\ \text { Cbat } & \text { cost of each battery } \\ \text { Nbat } & \text { number of batteries } \\ \text { Cinv } & \text { cost of inverter } \\ \text { Clp } & \text { life cycle cost of solar panels } \\ \text { Clw } & \text { life cycle cost of wind turbines } \\ C l b & \text { life cycle cost of batteries } \\ C l i n v & \text { life cycle cost of inverter } \\ \varepsilon & \text { inflation rate } \\ r & \text { real interest rate } \\ \alpha p o \mathcal{E} m & \text { maintenance rate per year } \\ N_{y} & \text { horizon of the project in years } \\ X w & \text { number of replacement of wind turbines } \\ l_{w} & \text { wind turbines lifetime } \\ X_{b} & \text { number of replacement time of batteries } \\ l_{b} & \text { life cycle year of the battery } \\ A E & \text { annual profits generated } \\ \text { OEM } & \text { annual operation and maintenance cost }\end{array}$

\section{References}

1. Bayod-Rújula, Á.A.; Haro-Larrodé, M.E.; Martínez-Gracia, A. Sizing criteria of hybrid photovoltaic-Wind systems with battery storage and self-consumption considering interaction with the grid. Sol. Energy 2013, 98, 582-591. [CrossRef]

2. González, A.; Riba, J.-R.; Rius, A.; Puig, R. Optimal sizing of a hybrid grid-connected photovoltaic and wind power system. Appl. Energy 2015, 154, 752-762. [CrossRef]

3. Sinha, S.; Chandel, S.S. Review of recent trends in optimization techniques for solar photovoltaic-Wind based hybrid energy systems. Renew. Sustain. Energy Rev. 2015, 50, 755-769. [CrossRef]

4. Khare, V.; Nema, S.; Baredar, P. Solar-wind hybrid renewable energy system: A review. Renew. Sustain. Energy Rev. 2016, 58, 23-33. [CrossRef]

5. Belmili, H.; Almi, M.F.; Bendib, B.; Bolouma, S. A computer program development for sizing stand-alone Photovoltaic-Wind hybrid systems. Energy Procedia 2013, 36, 546-557. [CrossRef]

6. Ma, T.; Yang, H.; Lu, L. A feasibility study of a stand-alone hybrid solar-wind-battery system for a remote island. Appl. Energy 2014, 121, 149-158. [CrossRef]

7. Al Busaidi, A.S.; Kazem, H.A.; Al-Badi, A.H.; Farooq Khan, M. A review of optimum sizing of hybrid PV-Wind renewable energy systems in oman. Renew. Sustain. Energy Rev. 2016, 53, 185-193. [CrossRef]

8. Conti, P.; Lutzemberger, G.; Schito, E.; Poli, D.; Testi, D. Multi-Objective Optimization of Off-Grid Hybrid Renewable Energy Systems in Buildings with Prior Design-Variable Screening. Energies 2019, 12, 3026. [CrossRef]

9. Xu, L.; Ruan, X.; Mao, C.; Zhang, B.; Luo, Y. An improved optimal sizing method for wind-solar-battery hybrid power system. IEEE Trans. Sustain. Energy 2013, 4, 774-785.

10. Saharia, B.J.; Zaheeruddin; Manas, M.; Ganguly, A. Optimal sizing and cost assesment of hybrid Renewable Energy Systems for Assam Engineering College. In Proceedings of the 2015 Annual IEEE India Conference (INDICON), New Delhi, India, 17-20 December 2015; pp. 1-6.

11. Faccio, M.; Gamberi, M.; Bortolini, M.; Nedaei, M. State-of-art review of the optimization methods to design the configuration of hybrid renewable energy systems (HRESs). Front. Energy 2018, 12, 591-622. [CrossRef]

12. Siddaiah, R.; Saini, R.P. A review on planning, configurations, modeling and optimization techniques of hybrid renewable energy systems for off grid applications. Renew. Sustain. Energy Rev. 2016, 58, 376-396. [CrossRef] 
13. Abdmouleh, Z.; Gastli, A.; Ben-Brahim, L.; Haouari, M.; Al-Emadi, N.A. Review of optimization techniques applied for the integration of distributed generation from renewable energy sources. Renew. Energy 2017, 113, 266-280. [CrossRef]

14. Waibel, C.; Wortmann, T.; Evins, R.; Carmeliet, J. Building energy optimization: An extensive benchmark of global search algorithms. Energy Build. 2019, 187, 218-240. [CrossRef]

15. Maleki, A.; Pourfayaz, F.; Rosen, M.A. A novel framework for optimal design of hybrid renewable energybased autonomous energy systems: A case study for Namin, Iran. Energy 2016, 98, 168-180. [CrossRef]

16. Caballero, F.; Sauma, E.; Yanine, F. Business optimal design of a grid-connected hybrid PV (photovoltaic)-wind energy system without energy storage for an Easter Island's block. Energy 2013, 61, 248-261. [CrossRef]

17. Hosseinalizadeh, R.; Shakouri, G.H.; Amalnick, M.S.; Taghipour, P. Economic sizing of a hybrid (PV-WT-FC) renewable energy system (HRES) for stand-alone usages by an optimization-simulation model: Case study of Iran. Renew. Sustain. Energy Rev. 2016, 54, 139-150. [CrossRef]

18. Katsigiannis, Y.A.; Georgilakis, P.S.; Karapidakis, E.S. Hybrid Simulated Annealing; Tabu Search Method for Optimal Sizing of Autonomous Power Systems with Renewables. IEEE Trans. Sustain. Energy 2012, 3, 330-338. [CrossRef]

19. Pradhan, A.K.; Kar, S.K. Modeling, Simulation and Economic analysis of Offgrid Hybrid Renewable Power System for an UnElectrified Village in Odisha. In Proceedings of the 2015 International Conference on Electrical, Electronics, Signals, Communication and Optimization (EESCO), Visakhapatnam, India, 24-25 January 2015.

20. Alsayed, M.; Cacciato, M.; Scarcella, G.; Scelba, G. Multicriteria optimal sizing of photovoltaic-wind turbine grid connected systems. IEEE Trans. Energy Convers. 2013, 28, 370-379. [CrossRef]

21. Ould Bilal, B.; Sambou, V.; Ndiaye, P.A.; Kébé CM, F.; Ndongo, M. Multi-objective design of PV-wind-batteries hybrid systems by minimizing the annualized cost system and the loss of power supply probability (LPSP). In Proceedings of the 2013 IEEE International Conference on Industrial Technology (ICIT), Cape Town, South Africa, 25-28 February 2013; pp. 861-868.

22. Shi, Z.; Wang, R.; Zhang, T. Multi-objective optimal design of hybrid renewable energy systems using preference-inspired coevolutionary approach. Sol. Energy 2015, 118, 96-106. [CrossRef]

23. Zeng, J.; Li, M.; Liu, J.F.; Wu, J.; Ngan, H.W. Operational Optimization of a Stand-alone Hybrid Renewable Energy Generation System based on an Improved Genetic Algorithm. In Proceedings of the IEEE Power \& Energy Society General Meeting, Providence, RI, USA, 25-29 July 2010; pp. 1-6.

24. Ogunjuyigbe, A.S.O.; Ayodele, T.R.; Akinola, O.A. Optimal allocation and sizing of PV/Wind/Split-diesel/ Battery hybrid energy system for minimizing life cycle cost, carbon emission and dump energy of remote residential building. Appl. Energy 2016, 171, 153-171. [CrossRef]

25. Sharafi, M.; ElMekkawy, T.Y.; Bibeau, E.L. Optimal design of hybrid renewable energy systems in buildings with low to high renewable energy ratio. Renew. Energy 2015, 83, 1026-1042. [CrossRef]

26. Kirthiga, M.V.; Daniel, S.A. Optimal sizing of hybrid generators for autonomous operation of a micro-grid. In Proceedings of the 2010 IEEE 26th Convention of Electrical and Electronics Engineers in Israel, Eliat, Israel, 17-20 November 2010; pp. 864-868.

27. Wu, Z.; Tazvinga, H.; Xia, X. Demand side management of photovoltaic-battery hybrid system. Appl. Energy 2015, 148, 294-304. [CrossRef]

28. MatWorks, I. MathWorks-Makers of MATLAB and Simulink. 2015. Available online: http://es.mathworks. com/index.html?s_tid=gn_logo (accessed on 24 April 2017).

29. EDSS. Essa Norma Para el Cálculo y Diseño de Sistemas de Distribución. 2004, p. 165. Available online: https:// www.essa.com.co/site/Portals/14/Docs/Norma\%20tecnica/Norma\%20T\%C3\%A9cnica\%20ESSA.pdf (accessed on 19 December 2019).

(C) 2019 by the authors. Licensee MDPI, Basel, Switzerland. This article is an open access article distributed under the terms and conditions of the Creative Commons Attribution (CC BY) license (http://creativecommons.org/licenses/by/4.0/). 